\title{
Educación emergente para las enseñanza de la bioestadística en enfermería
}

\section{(c) 198 \\ Juan Manuel Sánchez Soto \\ Magally Martínez Reyes \\ Anabelem Soberanes Martín}

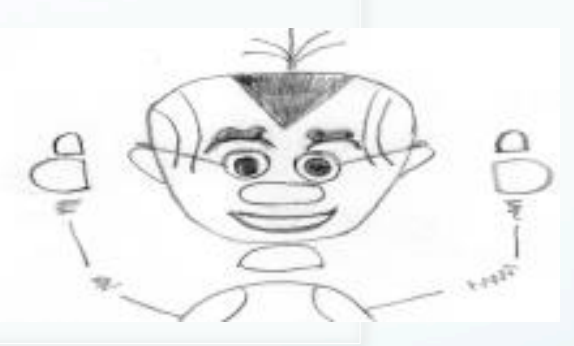

Centro Universitario Valle de Chalco, Universidad

Autónoma del Estado de México 


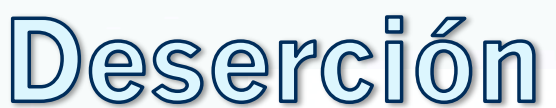

2023

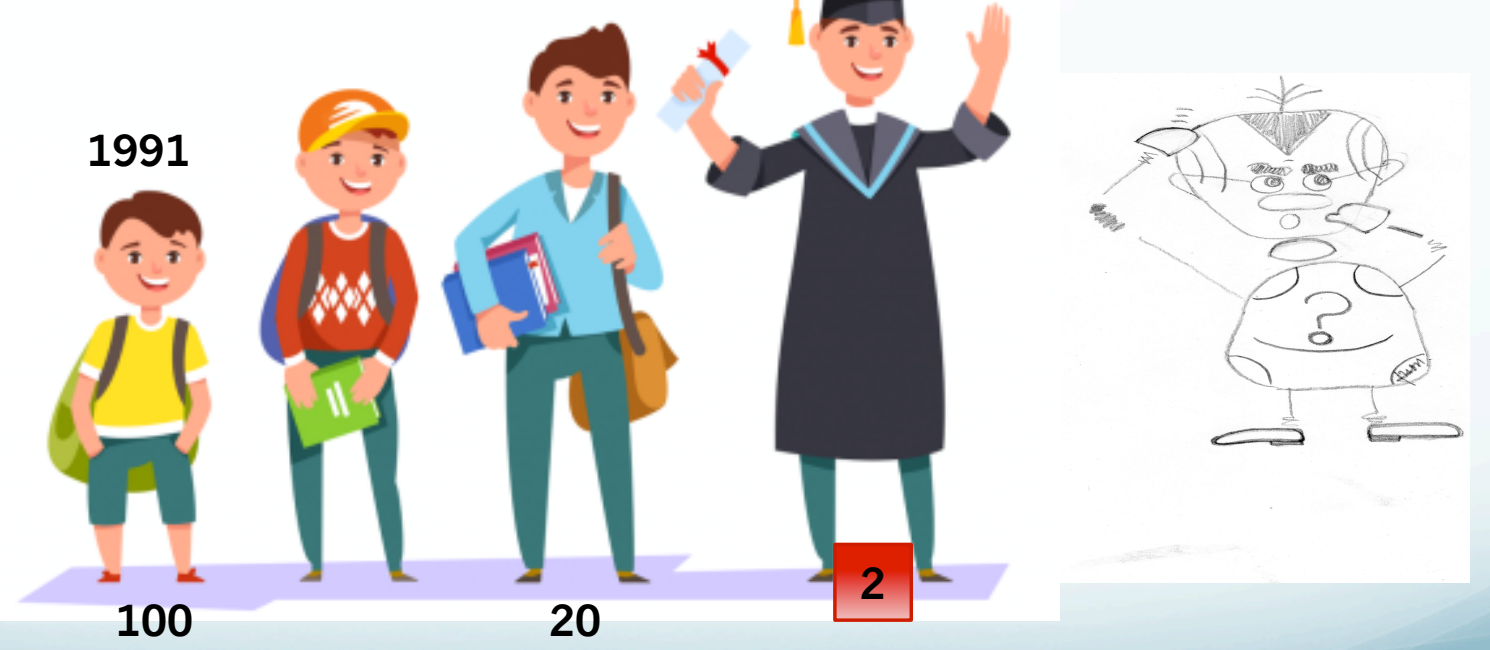

UNIVERSAL (2018). Deserción escolar, infrenable: SEP. Consultado el 1 de julio del 2019 en:

https://www.eluniversal.com. mx/nacion/sociedad/desercion-escolar-infrenable-sep 
Las pedagogías alternativas son un conjunto de estrategias innovadoras que abren caminos a posturas fundamentadas en tendencias educativas que pretenden ser renovadoras del hecho educativo.
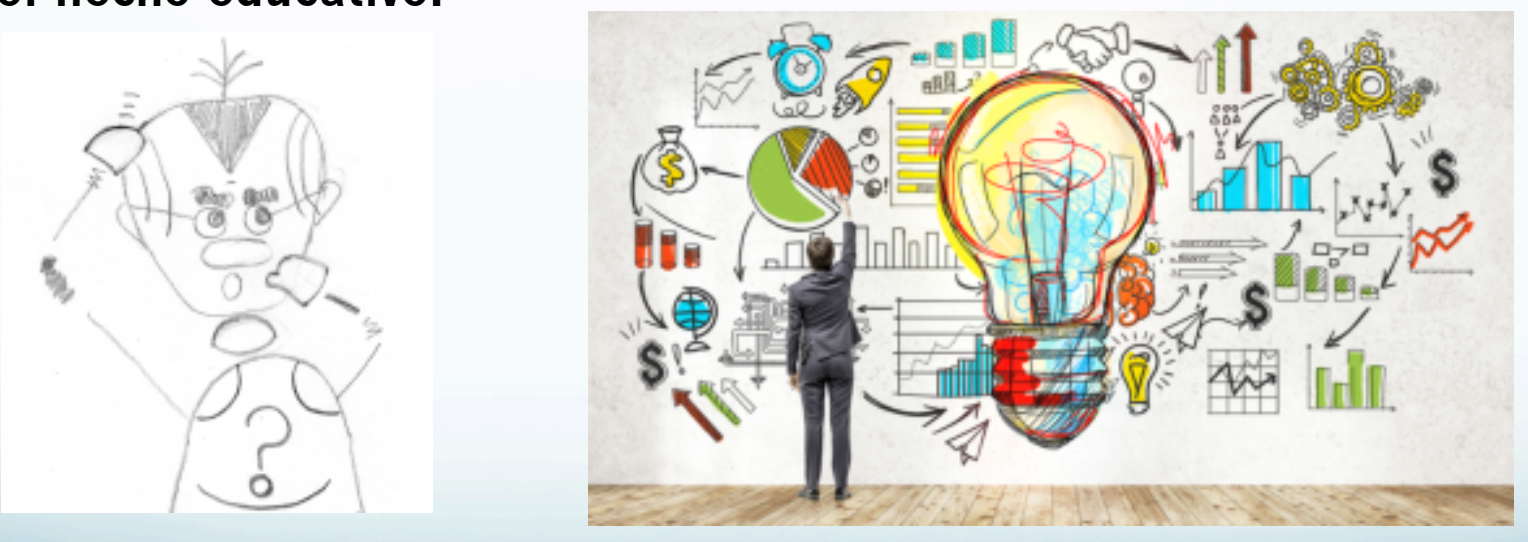

Alirio, A., Africano, B., Febres-Cordero, M. y Carrillo, T. (2011). Una aproximación a las pedagogías alternativas. Educere, 20 (66): 237-247. 


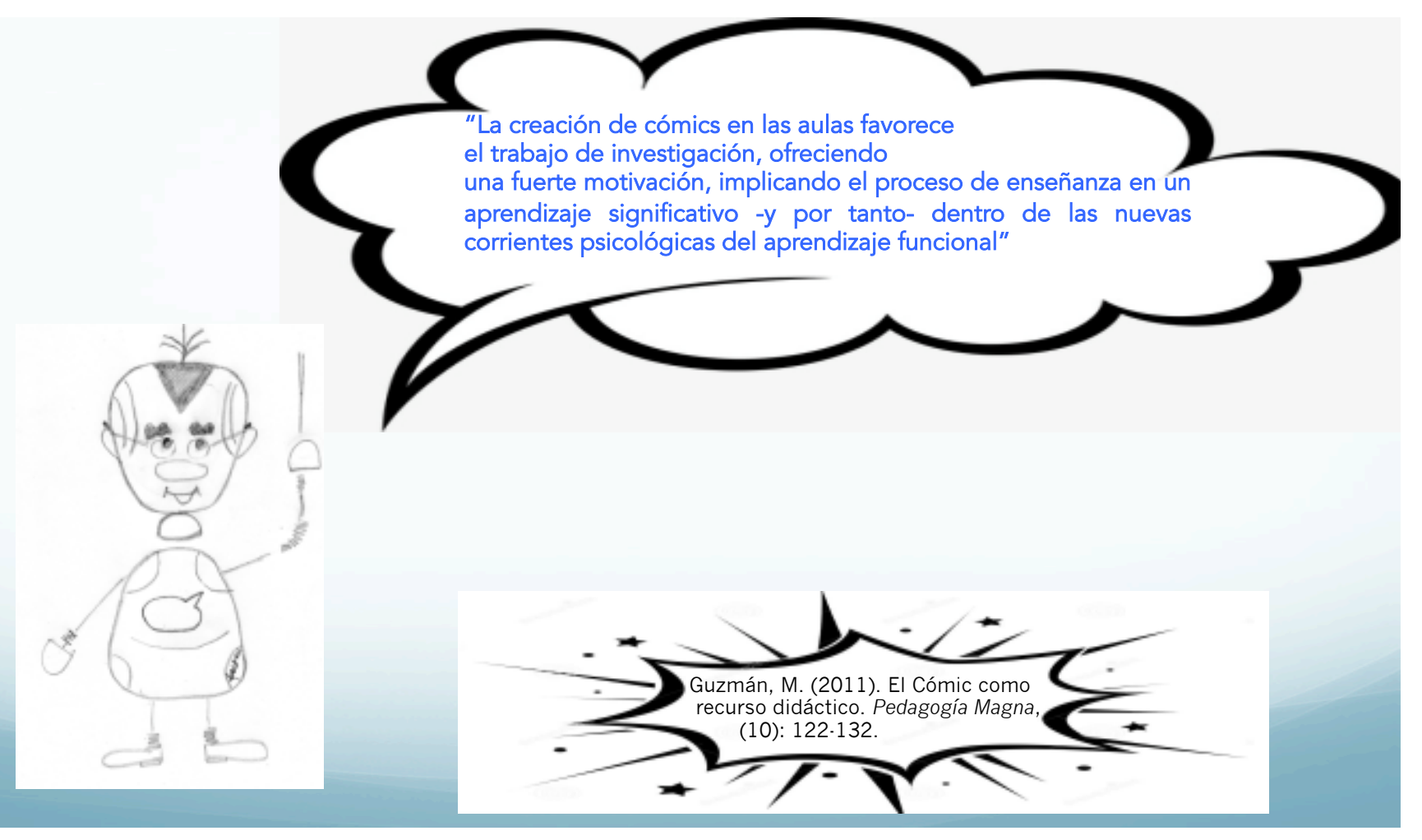




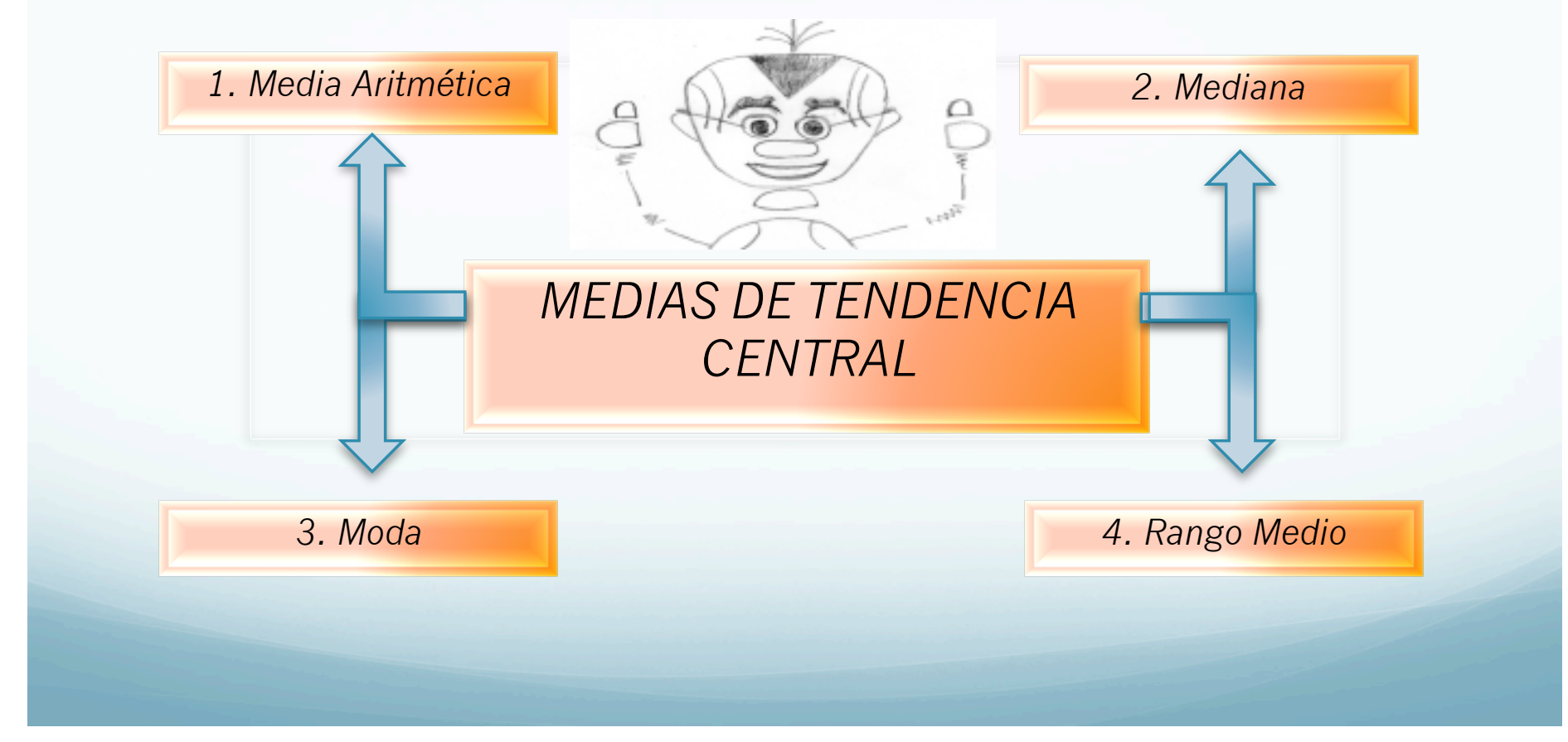




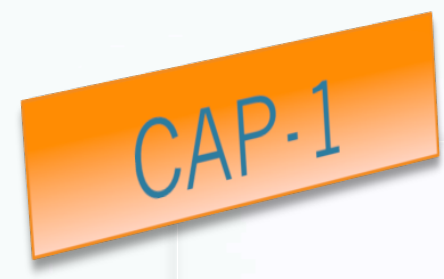

\section{MEDIA ARIMERTICA}

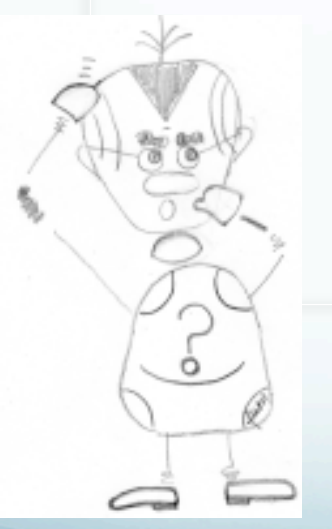

Es la sumatoria de cada uno de los elementos del grupo, dividido entre el número total de los mismos.<smiles>CCCCC</smiles>

Esto es muy sencillo, es cuando sacamos los promedios de cualquier grupo de datos.

Si deseamos saber el promedio de nuestras calificaciones, sumamos la calificación de cada una de las materias y la dividimos entre el total de ellas. 


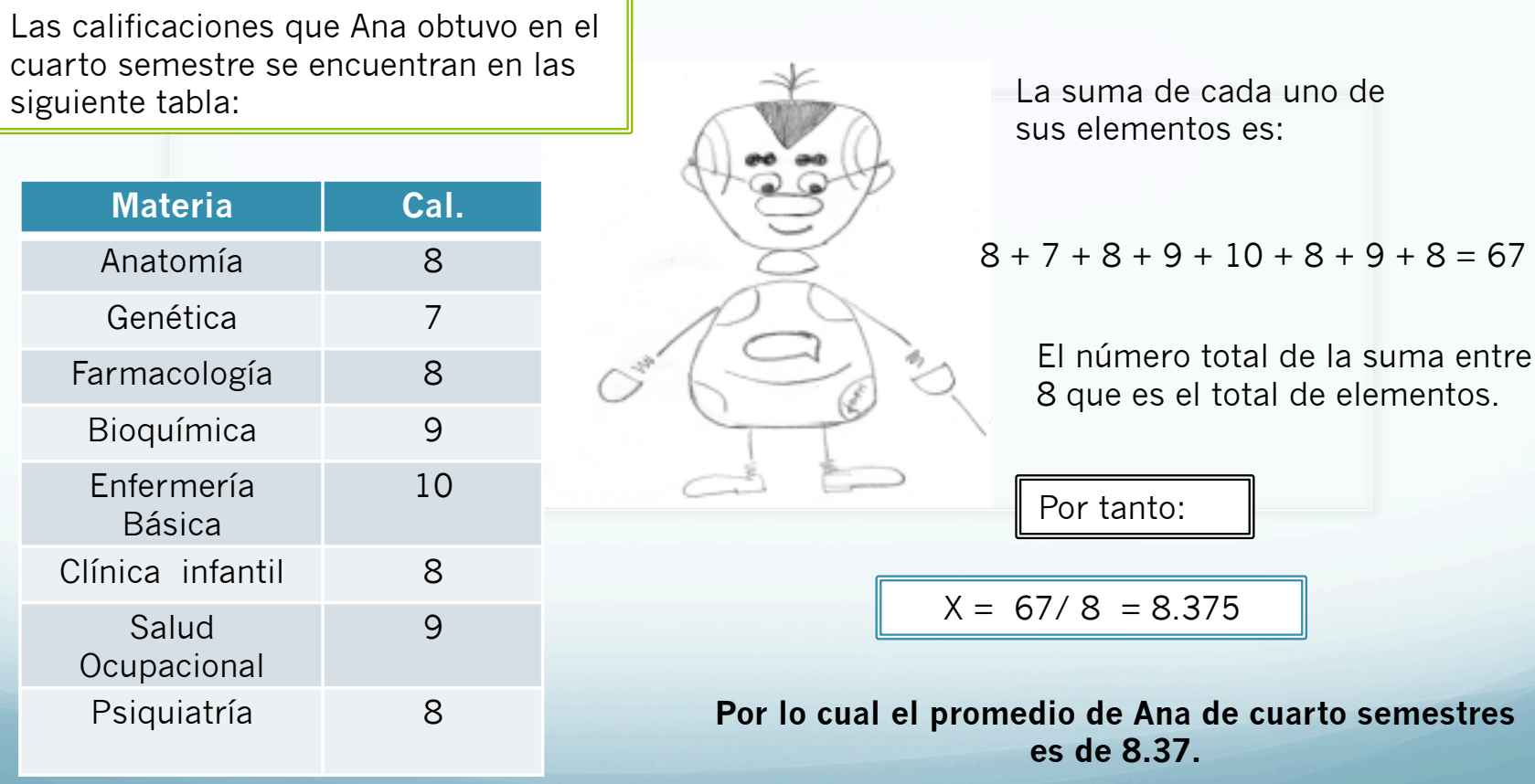

\begin{tabular}{|c|c|}
\hline Materia & Cal. \\
\hline Anatomía & 8 \\
\hline Genética & 7 \\
\hline Farmacología & 8 \\
\hline Bioquímica & 9 \\
\hline Enfermería & 10 \\
\hline Básica & 8 \\
\hline Clínica infantil & 9 \\
\hline Salud & 8 \\
\hline Ocupacional & \\
\hline Psiquiatría & \\
\hline
\end{tabular}

El número total de la suma entre 8 que es el total de elementos.

\section{Por tanto:}

$X=67 / 8=8.375$

Por lo cual el promedio de Ana de cuarto semestres es de 8.37. 


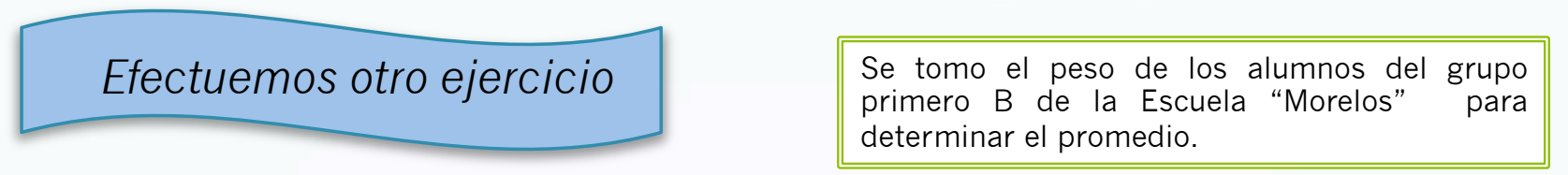

\begin{tabular}{|l|l|l|l|l|l|l|l|l|}
\hline 18.7 & 20.2 & 21.5 & 19.5 & 18.9 & 22.4 & 22.9 & 19.2 & 23.2 \\
\hline 19.6 & 21.8 & 23.7 & 22.1 & 25.0 & 20.7 & 21.2 & 20.4 & 18.5 \\
\hline
\end{tabular}

\section{Realizamos la Sumatoria}

$18.7+20.2+21.5+19.5+18.9+22.4+22.9+19.2+23.2+19.6+21.8+23.7+22.1+25.0+20.7+21.2+26$

El total de los datos es 18 por tanto:

$$
X=379.5 / 18=21.08
$$

Por lo cual el promedio de peso de los alumnos de grupo de primero $B$ es de 21.08

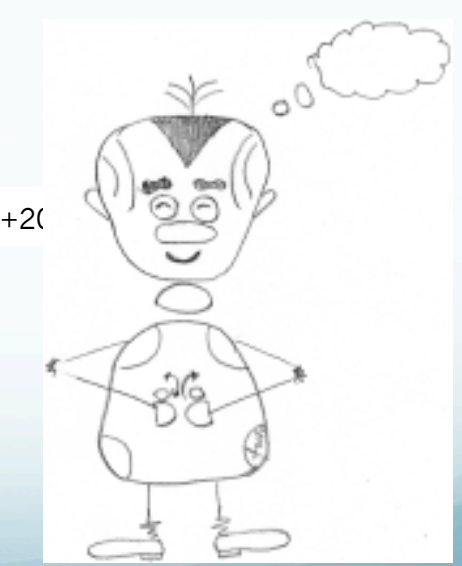




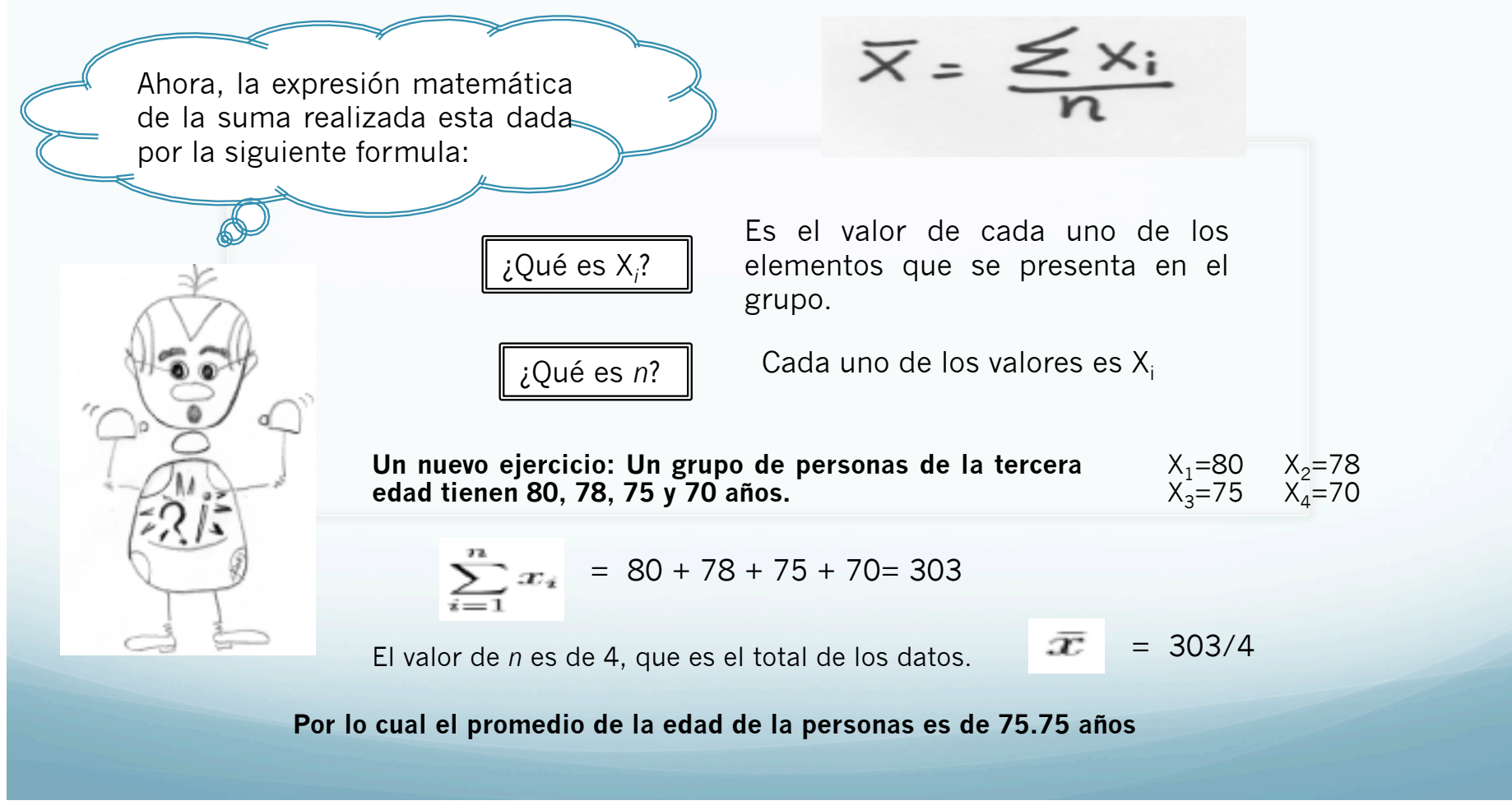




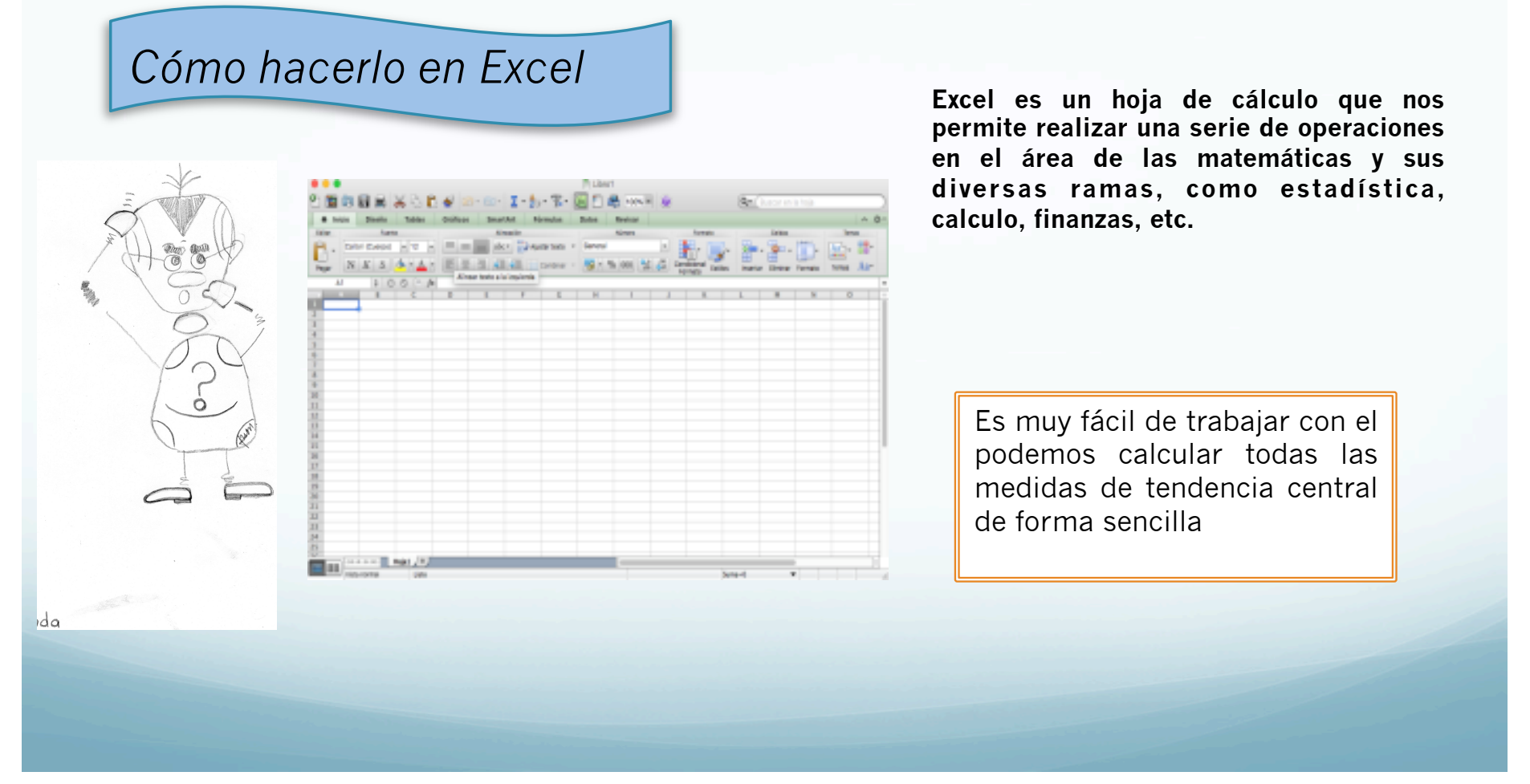




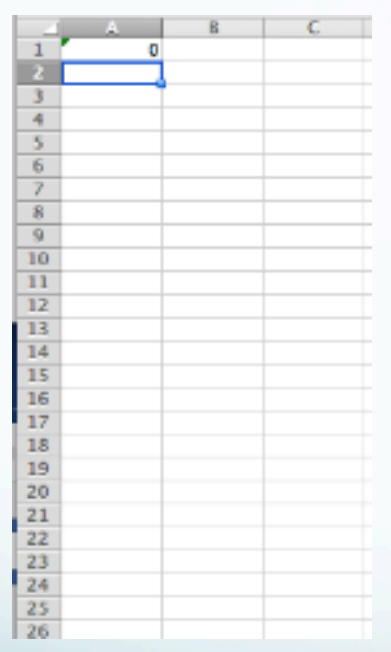

\section{Seleccionamos}

una de las

columnas en la

c u a l e s

colocaremos

nuestros datos

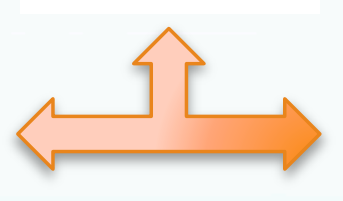

\begin{tabular}{|c|c|c|}
\hline & A & B \\
\hline 1 & 4 & \\
\hline 2 & 5 & \\
\hline 3 & 6 & \\
\hline 4 & 5 & \\
\hline 5 & 6 & \\
\hline 6 & 8 & \\
\hline 7 & 7 & \\
\hline 8 & 3 & \\
\hline 9 & 2 & \\
\hline 10 & 4 & \\
\hline 11 & 5 & \\
\hline 12 & 7 & \\
\hline 13 & 6 & \\
\hline 14 & 5 & \\
\hline 15 & 2 & \\
\hline 16 & & \\
\hline 17 & & \\
\hline
\end{tabular}

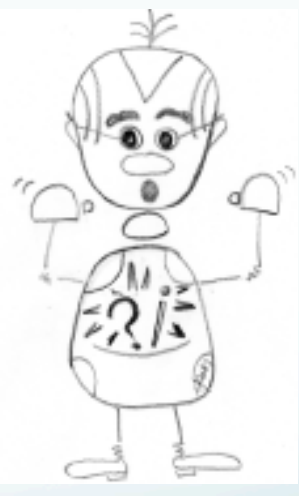




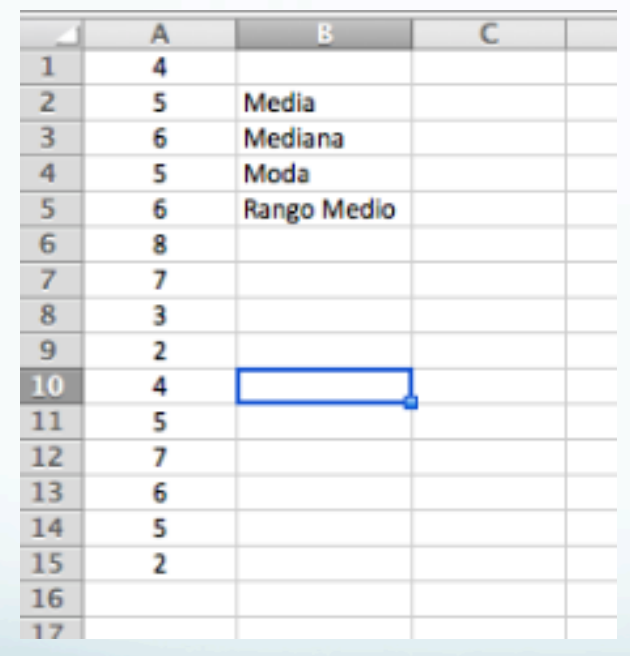

En la celda continua colocamos los parámetros que vamos a calcular.

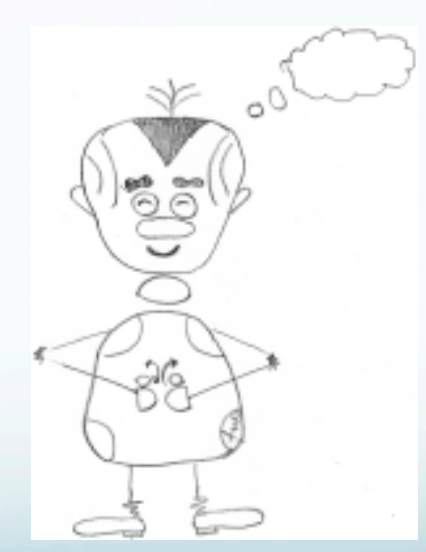




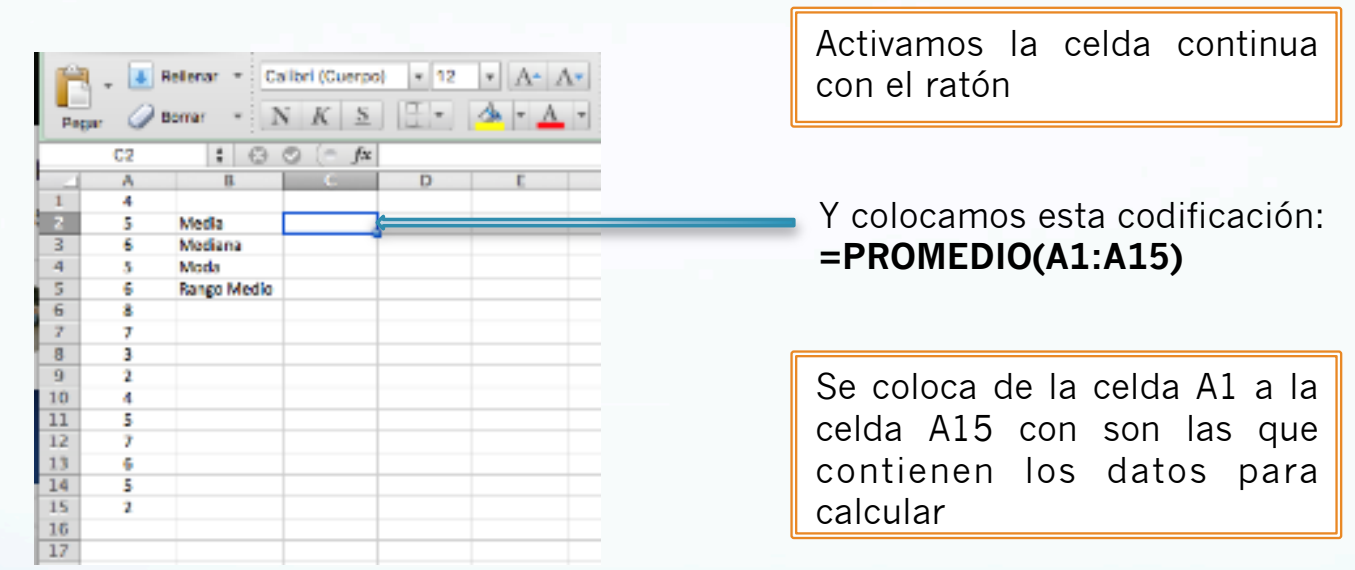


Codificación es muy importante que no tengas

faltas de ortografía, colocar los paréntesis la

celda inicial los dos puntos y la celda final, y por

último le damos enter.
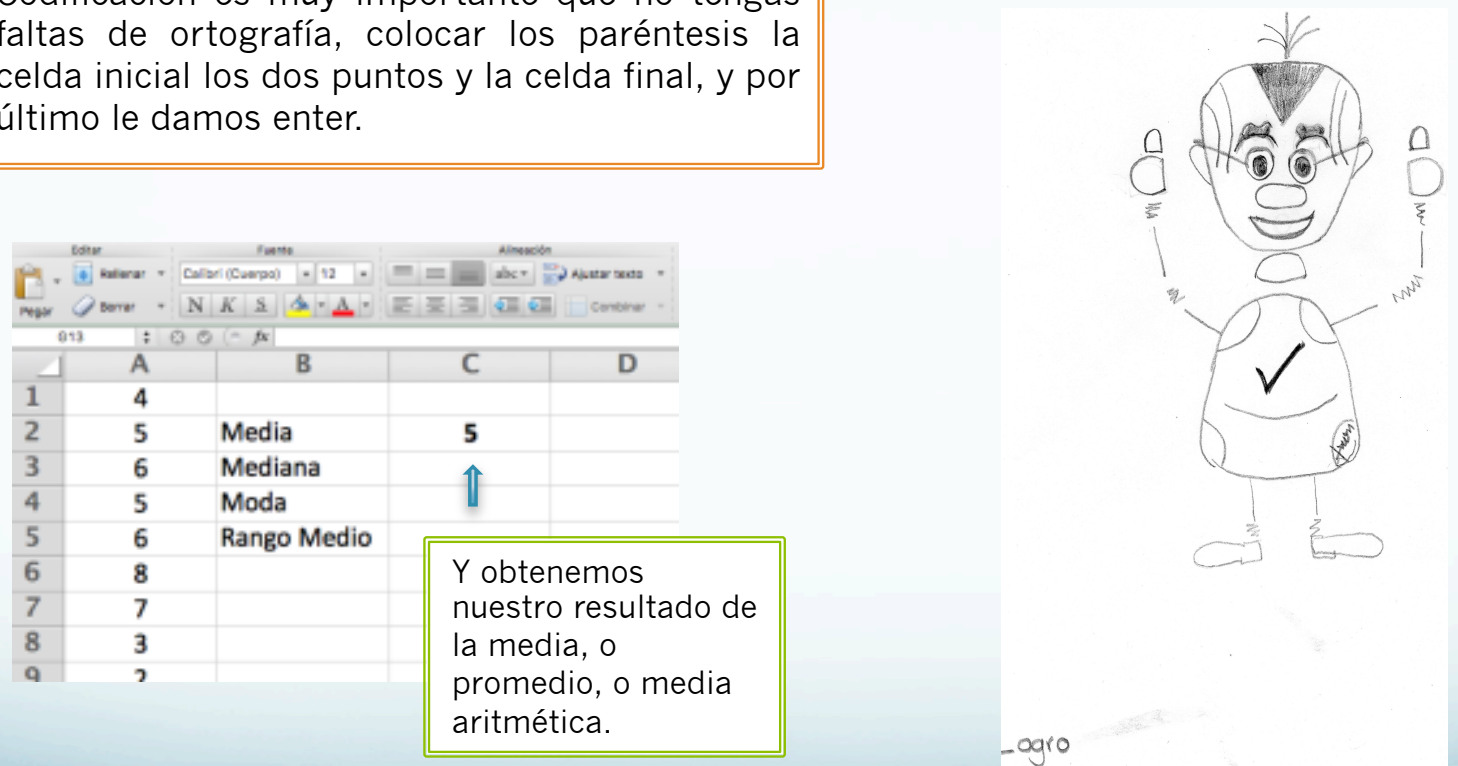


\section{Ejercicios Complementarios}

De los siguientes ejercicios determina las medidas de tendencia central

1. En un centro de salud se toma el peso de cada uno de los pacientes, obteniendo los siguientes datos en kilogramos:

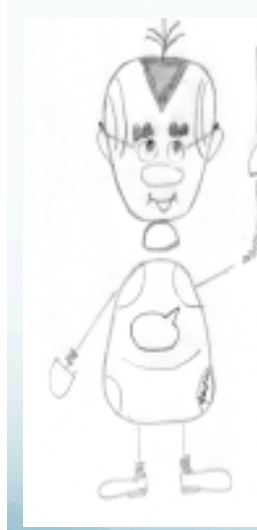

78

66
56

$\begin{array}{ll}80 & 61 \\ 78 & 71\end{array}$

87
70

$78 \quad 45$

77

$\begin{array}{ll}61 & 60 \\ 87 & 74\end{array}$

$\begin{array}{ll}59 & 72 \\ 82 & 69\end{array}$

76
48

2. En la primaria «Morelos» se toma la talle de los niños de sexto B, obteniendo los siguientes datos en metros:

$\begin{array}{llllllllllll}1.02 & 1.05 & 1.10 & 1.09 & 1.01 & 1.05 & 1.08 & 1.10 & 1.121 & 1.17 & 1.07 & 1.08\end{array}$

3. En el laboratorio de análisis clínicos se pesa cada una de las tabletas de una caja (30 tabletas) de ácido acetil salicílico para determina la homogeneidad del peso, obteniendo los siguientes datos en gramos:

$\begin{array}{llllllllll}0.35 & 0.31 & 0.29 & 0.33 & 0.28 & 0.31 & 0.32 & 0.33 & 0.36 & 0.28 \\ 0.32 & 0.32 & 0.35 & 0.29 & 0.28 & 0.31 & 0.33 & 0.35 & 0.32 & 0.32 \\ 0.31 & 0.30 & 0.32 & 0.29 & 0.33 & 0.32 & 0.31 & 0.32 & 0.29 & 0.30\end{array}$




\title{
Prueba Piloto
}

\author{
Dos estudiantes que \\ reprobaron el curso \\ Dos estudiantes que no \\ de bioestadística \\ han cursado \\ bioestadística
}

Calificaciones de los ejercicios complementarios

$15 / 15$

$14 / 15$

$14 / 15$

$12 / 15$ 


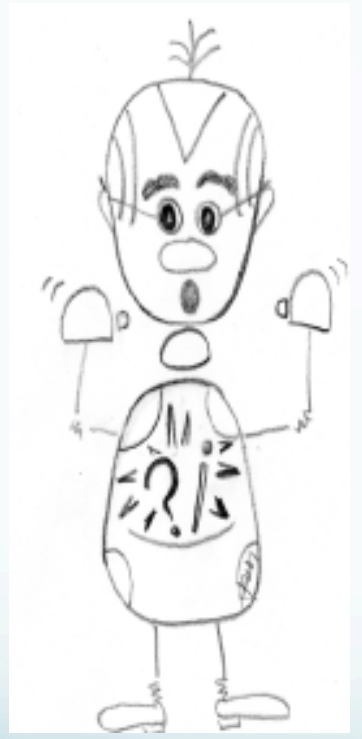

BioMate para la enseñanza de la bioestadística en la licenciatura de Enfermería, como un proceso de aprendizaje basado en problemas.

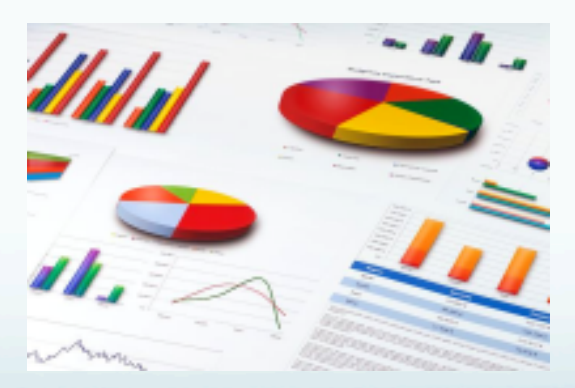




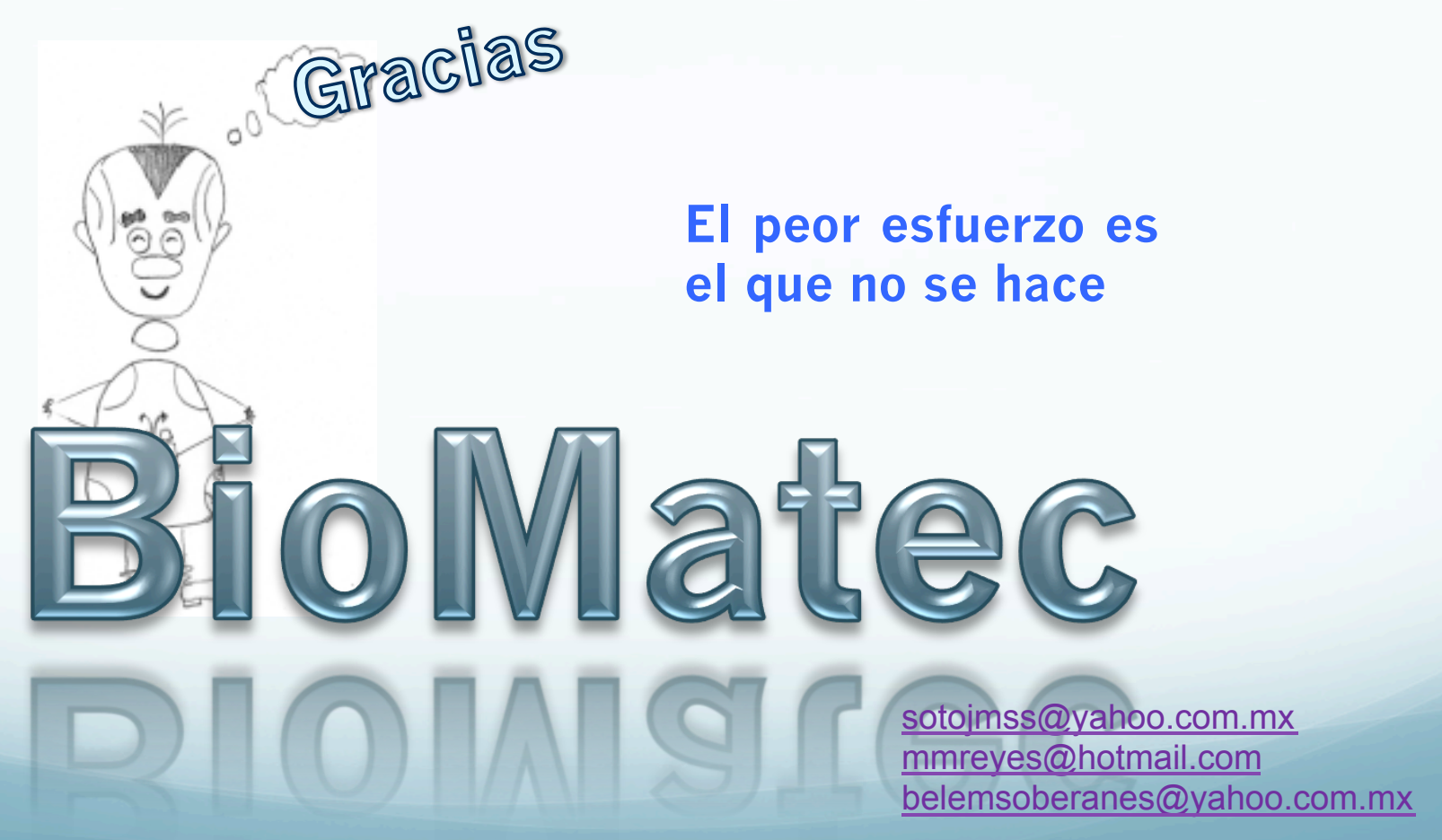

